\title{
Watershed Response to Bias-Corrected Improved Skilled Precipitation and Temperature under Future Climate - A Case Study on Spencer Creek Watershed, Ontario, Canada
}

\section{Sadik Ahmed and loannis Tsanis*}

Department of Civil Engineering, McMaster University, Hamilton, Ontario L8S 4L7, Canada

\begin{abstract}
It is widely acknowledged that the statistical properties of precipitation and temperature will change under the future climate condition, and this will cause a significant impact on water resources and its management at watershed scale. This study investigated the hydrological response to climate change for Spencer Creek watershed located in Southern Ontario, Canada. The precipitation and temperature projection used in this study were obtained from the North American Regional Climate Change Assessment Program (NARCCAP) climate simulations. NARCCAP climate projections were bias- corrected for meteorological stations representative of the watershed. The biascorrected NARCCAP climate projections were used as input in a calibrated hydrological model Hydrologiska Byråns Vattenbalans-avdelning (HBV) to simulate flows at the outlet of the watershed. The improvement of bias-corrected NARCCAP precipitation and temperature is revealed by Brier and Rank Probability Skill Score (BSS and RPSS, respectively). The comparison of current and future simulated flow results reveals an increase in winter daily average flows and decrease in other seasons, and approximately $13 \%$ increase in annual evapotranspiration under future climate condition. An increase in high flows and decrease in low flows under future climate is revealed by flowduration analysis.
\end{abstract}

Keywords: Climate change; Bias correction; Hydrology; Watershed; Canada

\section{Introduction}

The recent Intergovernmental Panel on Climate Change (IPCC) Assessment Report [1] indicates that our climate is undergoing substantial warming, and it is likely that an increasing trend of extreme precipitation will continue. The watershed hydrology will be affected by climate change in many ways because the hydrological cycle is linked with changes in atmospheric temperature and radiative fluxes [2]. The changes in temperature will have a significant effect on the hydrological processes that involve precipitation, snowmelt, evapotranspiration, soil moisture and flow. The prediction of the forthcoming climate change on hydrological processes is vital in water resources management and planning. In this study, climate change impact on hydrological processes has been performed by forcing climate model output to a hydrological model in order to evaluate changes in future flow in the Spencer Creek watershed located in Southern Ontario.

In the last decade, researchers as well as users have shown particular interest in the hydrological impact of climate change. Past research on climate change impact assessment revealed that the hydrological regime of different watersheds could be significantly modified due to the anticipated changes in temperature and precipitation under future climate during the present century [3-5]. The assessment results of climate change impact on hydrology at the watershed scale vary significantly with the climate model projections, greenhouse gas emission scenarios, data downscaling/ correction techniques, and hydrologic models. Grillakis et al. [3] examined the climate change impact on future hydrology of Spencer Creek watershed. The study revealed inter-annual trends for precipitation and temperature both in the past data and future simulation. The analysis shows an annual average precipitation increase by approximately $10 \%$ to $15 \%$ and temperature increase by approximately $+2.2^{\circ} \mathrm{C}$ and $+2.3^{\circ} \mathrm{C}$ at Hamilton Airport and Hamilton RBG. The study also shows that the yearly average flow at Spencer Creek at Dundas increases by about $12 \%$ when future projected flows are compared with the observed flow. Sultana and Coulibaly [4] assessed the climate change impact on hydrological processes of this watershed using a distributed coupled MIKE SHE/MIKE 11 hydrologic model and the projected daily precipitation and temperature from Canadian global climate model (CGCM 3.1). The downscaled GCM predictions show a $14-17 \%$ increase in the annual mean precipitation and $2-3^{\circ} \mathrm{C}$ increase in annual mean maximum temperature. The coupled hydrologic model predicted about $1-5 \%$ annual decrease in snow storage, $1-10 \%$ increase in annual ET, $0.5-6 \%$ decrease in the annual groundwater recharge, 10 $25 \%$ increase in annual stream flows for all sites for the 2050s when downscaled GCM scenarios were used. Boyer et al. [5] assessed the impact of climate change on the hydrology of St. Lawrence tributaries (Quebec, Canada) located about $650 \mathrm{~km}$ northeast of Spencer Creek. The hydrological model HSAMI was used to produce flow in the future by inputting GCM projections for three 30 year horizons (2010-2039, 2040-2069 and 2070-2099, respectively referred to as 2020s, 2050s and 2080s). The future daily climate (precipitation and temperature) for three 30 year horizons were produced by adding anomalies (monthly mean difference between GCMs in the future and the reference period 1961-1990) to the observed temperature and precipitation during the reference period. The study results indicate that the regime will gradually shift from snow to rain. Most of the future flow simulations show an increase in winter discharge and a decrease in spring discharge.

*Corresponding author: loannis Tsanis, Department of Civil Engineering, McMaster University, 1280 Main Street West, Hamilton, Ontario L8S 4L7, Canada, Tel: +19055259140; E-mail: tsanis@mcmaster.ca

Received May 03, 2016; Accepted June 15, 2016; Published June 25, 2016 Citation: Ahmed S, Tsanis I (2016) Watershed Response to Bias-Corrected Improved Skilled Precipitation and Temperature under Future Climate - A Case Study on Spencer Creek Watershed, Ontario, Canada. Hydrol Current Res 7: 246. doi:10.4172/2157-7587.1000246

Copyright: (C) 2016 Ahmed S, et al. This is an open-access article distributed unde the terms of the Creative Commons Attribution License, which permits unrestricted use, distribution, and reproduction in any medium, provided the original author and source are credited. 
The study results also show that the center volume date for the winter/ spring period is expected to be in advance 22-34 days depending on the location of the watershed.

The most widely used approach to predict climate change impact on hydrological processes is done by inputting climate model simulations into hydrological models. The climate model (GCM or RCM) provides gridded data, and the climate projected from it is not the same as the climate coming from the observations. Therefore, modelers use different techniques for establishing relationship between climate model outputs and observations for correcting the climate model projections both for current and future period to get more realistic results from the hydrological model. A number of dynamical and statistical downscaling methods are available to downscale climate model gridded data at the target points where the meteorological or rainfall stations are located [6-10]. Sharma et al. [11] examined the necessity of correction of raw RCM data by using a statistical downscaling method (SDSM) and a data-driven technique called a time-lagged feedforward network (TLFN) on raw CRCM4.2 data. They revealed that the downscaling did improve raw RCM precipitation, and consequently, the downscaled CRCM4.2 data improves the HBV hydrologic model ability to simulate streamflow accurately as compared to the use of the raw CRCM4.2 data. Although the statistical downscaling methods have been used in many studies, the application and calibration of this method are complex and highly dependent on expert judgment [12]. The regional climate models (RCMs), generated from dynamical downscaling methods, provide climate projections at much finer scale that is largely used in hydrological impact studies in many watersheds around the world. However, recent studies $[11,13]$ revealed that there are systematic differences between the raw RCMs output and the observations, and the bias-correction methods alternative to statistical and dynamical downscaling method has shown effectiveness in removing the bias between raw RCMs output and the observations [13,14]. The bias correction methods used by Ines and Hansen [15] and Samuel et al. [13] have been used in this study for correcting the NARCCAP climate model output. One of the novelty of this study is that two probabilistic verification measures, namely the Brier skill score (BSS) and the rank probability skill score (RPSS) have been used in this study to assess the improvement of NARCCAP precipitation and temperature data when bias correction method was applied.

The availability of higher spatial and temporal resolution climate data, provided by the NARCCAP created from multiple GCMs and RCMs, has facilitated the climate change impact studies. Using ensemble climate model data will provide multiple possible estimations of flow regime, which assists the water manager towards a sustainable planning and design. Because of the high uncertainty in the climate model projections, Mearns et al. [16] emphasized on the use of ensemble climate model projections for climate change impact study by using climate model simulations. NARCCAP provides both precipitation and temperature time series for both current and future period for eight RCM+GCM pairs at same spatial scale. All the available climate model data have been used in this study. A number of hydrological models have been used by the researchers for climate change impact studies in different countries. In this study, a semi-distributed conceptual model, $\mathrm{HBV}$, was chosen for hydrologic simulation using bias-corrected NARCCAP projections. The motivation of choosing this particular model is that the model was used in previous studies $[3,17,18]$ on Canadian watersheds and showed a good performance.

These recent studies on hydrological impact analysis indicate an overall increasing trend in the mean annual flow in Canadian watersheds. However, further investigation of extreme events such as high and low flow analyses is required. This study focused on the investigation of climate change impact on high and low flows using a number of climate model simulations. The overall objective of this study is to investigate the climate change impact on hydrological processes by using bias-corrected NARCCAP climate model projections for Spencer Creek watershed located in Southern Ontario, Canada. The objective was achieved by correcting the bias of raw NARCCAP precipitation and temperature time series, assessment of improvement in bias-corrected NARCCAP projections, performing hydrologic simulation and assessment of flow regime under current and future climate conditions.

\section{Study Area and Data}

\section{Study area}

The case study area for this study is Spencer Creek watershed located in the Southern Ontario, Canada and is shown in Figure 1. The watershed has an area of $160.4 \mathrm{~km}^{2}$. The surface runoff in the watershed is collected by an extensive network of rivers and stream and discharged into Cootes Paradise at the western end of Lake Ontario. The land-use of the study area can be also characterized by agricultural land use, forest area, wetlands and the urban and paved area in the lower part of the watershed. The watershed is complex because of its extensive river and stream network, heterogeneous soil property and diverse land use [19].

\section{Observed hydro-meteorological data}

The observed daily precipitation (total precipitation in the form of liquid and snow, measured in $\mathrm{mm}$ ) and temperature (in ${ }^{\circ} \mathrm{C}$ ) data were obtained from meteorological stations; namely the Hamilton Airport, Hamilton RGB, Hamilton RBG CS meteorological station. The meteorological data for 1971-2014 at the stations were collected

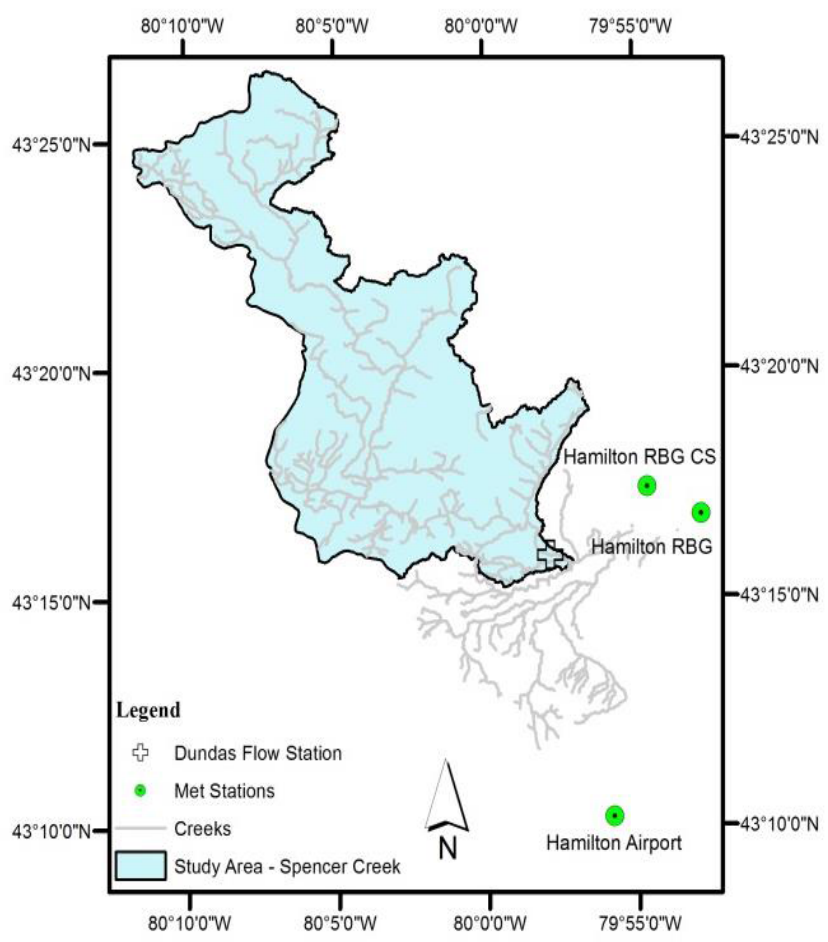

Figure 1: Map of the study area. 
from Environment Canada. The observed daily flow data for 30 years, from 1985 to 2014, were obtained for a hydrometric station namely Spencer Creek at Dundas (station ID 02HB007) located at latitude and longitude of $43.27^{\circ} \mathrm{N}$ and $79.96^{\circ} \mathrm{W}$, respectively. The daily flow data were collected from Water Survey Canada. The climate of the study area is humid-continental. Based on the meteorological data from 1971 to 2014 at Hamilton Airport, the daily average maximum and minimum temperatures are $13.4^{\circ} \mathrm{C}$ and $4^{\circ} \mathrm{C}$, and extreme maximum $37.4^{\circ} \mathrm{C}$ and extreme minimum temperature $-30^{\circ} \mathrm{C}$ were observed on 7 July, 1988 and 16 January, 2004, respectively. The yearly average precipitation is $893.2 \mathrm{~mm}$ based on data from 1971 to 2014 at Hamilton Airport, and the maximum daily rainfall and precipitation $107 \mathrm{~mm}$ were observed on 26 July, 1989. The yearly average flow is $2.02 \mathrm{~m}^{3} / \mathrm{s}$ with highest and lowest monthly average of $4.14 \mathrm{~m}^{3} / \mathrm{s}$ and $0.59 \mathrm{~m}^{3} / \mathrm{s}$ on March and August, respectively and the maximum daily average flow $32.4 \mathrm{~m}^{3} / \mathrm{s}$ was observed on 14 March 2010. These values were obtained based on the available daily time series data from 1985 to 2014 observed at hydrometric station namely Spencer Creek at Dundas.

\section{NARCCAP climate data}

The North American Regional Climate Change Assessment Program (NARCCAP) $[20,21]$ is an international program that serves the high resolution climate scenario for the United States, Canada, and Northern Mexico. It provides the data sets in order to investigate uncertainties in regional scale projections of future climate and generate climate change scenarios for use in impacts research. All the NARCCAP future simulations are driven by a GCM that follows greenhouse gas and aerosol concentration based on A2 emission scenario described in the Special Report on Emissions Scenarios (SRES) [22]. NARCCAP provides data produced by several RCM+GCM pairs, and this study used eight $\mathrm{RCM}+\mathrm{GCM}$ pairs simulated precipitation and temperature time series. The names of the RCMs and GCMs/drivers produced the data, used in this study, are listed in Table 1.

The NARCCAP output data are provided at a gridded horizontal resolution of $50 \mathrm{~km}$, and the precipitation and temperature (maximum and minimum) are provided for three hourly and daily temporal resolutions, respectively. The NARCCAP experimental output spans for two time periods of 33 years - the first time span is for the current/historical period spanning from 1968 to 2000, and the second time span is for the future span from 2038-2070. These two periods permit assessment of mid twenty-first century changes relative to late twentieth century climate. It is notable that the first three years, the spin-up periods [23], of both current and future simulation have been discarded in this study. NARCCAP data are stored in the NetCDF files in $2 \mathrm{D}$ arrays. The array dimensions (yc, xc) for the Hamilton Airport, Hamilton RBG/Hamilton RBG CS are found from the grid cell maps for each RCM. The array dimensions (yc, xc) of nearest point of Hamilton Airport for CRCM, HRM3, RCM3 and WRFG are $(51,100),(57,105)$, $(44,94)$ and $(48,93)$, respectively, and array dimensions (yc, xc) of nearest point of Hamilton RBG/Hamilton RBG CS for CRCM, HRM3 and RCM3, WRFG are $(51,100),(58,105),(45,93)$ and $(48,93)$.

\section{Methodology}

The procedure followed in this study involves (1) bias correction of NARCCAP precipitation and temperature time series data and analysis of skill score; (2) transforming bias-corrected precipitation and temperature into flows and evapotranspiration using a hydrological model, and (3) comparing hydrologic regime under current and future climate.

\section{Bias correction}

The NARCCAP temperature and precipitation data are gridded areal average, and not point estimates. Bias correction method is used to remove bias between climate model simulated data and observation at a point location to get more accurate results from the hydrological model when NARCCAP data are inputted.

The bias-correction method presented by Ines and Hansen [15] was used to correct the frequency and the intensity of daily precipitation of NARCCAP. This two-step procedure corrects the frequency of daily precipitation at first, and then it corrects the intensity for each of 12 calendar months. The mean precipitation $\overline{\mathrm{X}}_{(\mathrm{m})}\left(\mathrm{mmd}^{-1}\right)$ in calendar month $\mathrm{m}$ is the product of mean intensity, $\mu_{1}\left(\mathrm{~mm} \mathrm{wd}^{-1}\right)\left(\mathrm{wd}^{-1}\right)$ (is wet day, for a threshold $0.1 \mathrm{~mm}$ ) and relative frequency, $\pi\left(\mathrm{wd} \mathrm{d}^{-1}\right)$. Therefore, the correction of any bias of these two components also corrects the monthly total precipitation. In this study, this bias-correction method was applied to remove the bias between the daily precipitation data from NARCCAP and observations at Hamilton Airport and Hamilton RBG meteorological stations.

In the first step in order to correct the frequency of precipitation, the empirical distribution of the raw NARCCAP precipitation was truncated above the $\bar{x}_{\text {NARCCAP }}$ threshold value, in such a way that the mean frequency of precipitation above the threshold matches the observed mean precipitation frequency. The threshold value $\bar{x}_{\text {NARCCAP }}$ are calculated from the observed and NARCCAP precipitation distributions as show in the following equation,

$$
\bar{x}_{\text {NARCCAP }}=F_{\text {NARCCAP }}^{-1}\left(F_{\text {obs }}(\bar{x})\right)
$$

Where $\mathrm{F}($.$) and \mathrm{F}^{-1}($.) denotes the cumulative distribution function $(\mathrm{CDF})$ and its inverse, and subscripts indicate NARCCAP precipitation forecasts or observed_daily precipitation. The threshold observed precipitation amount $(\bar{x})$ of a day was set to $0.1 \mathrm{~mm}$ to define wet day.

In the second step to correct the intensity of precipitation, a twoparameter gamma distribution as shown in Equation 2 was used to fit the truncated daily NARCCAP and observed precipitation data, and then CDF of the truncated daily NARCCAP precipitation data are mapped to the CDF of the observed data as shown in Equation 3.

\begin{tabular}{|c|c|c|}
\hline RCM+GCM Pairs & RCM & GCM/Drivers \\
\hline CRCM+CCSM & Canadian Regional Climate Model [24] & Community Climate System Model [29] \\
\hline CRCM+CGCM3 & Canadian Regional Climate Model [24] & Third Generation Coupled Global Climate Model [30] \\
\hline HRM3+GFDL & Hadley Regional Model 3 [25] & Geophysical Fluid Dynamics Laboratory GCM [31] \\
\hline HRM3+HADCM3 & Hadley Regional Model 3 [25] & Third Generation Coupled Global Climate Model [30] \\
\hline RCM3+CGCM3 & Regional Climate Model version 3 [26,27] & Geophysical Fluid Dynamics Laboratory GCM [31] \\
\hline RCM3+GFDL & Regional Climate Model version 3 [26,27] & Community Climate System Model [29] \\
\hline WRFG+CCSM & Weather Research Forecasting Model Grell [28] & Third Generation Coupled Global Climate Model [30] \\
\hline WRFG+CGCM3 & Weather Research Forecasting Model Grell [28] & Toded \\
\hline
\end{tabular}

Table 1: List of RCM+GCM data pairs used in this study. 


$$
\begin{aligned}
& F_{G}(x, \alpha, \beta)=\frac{1}{\beta_{x}^{\alpha} \tilde{\mathrm{A}}(\alpha)} x^{\alpha-1} \exp \left(-\frac{x}{\beta}\right) ; x \geq \bar{x} \\
& F_{G}(x, \alpha, \beta)=\int_{\bar{x}}^{x} f(t) d t
\end{aligned}
$$

Where the shape parameter $(\alpha)$ and the scale parameter $(\beta)$ of the gamma distribution are determined by Maximum Likelihood Estimation. The corrected NARCCAP precipitation amount $x^{\prime}$ on day $\mathrm{i}$ is calculated by substituting the fitted gamma CDFs into the following equation:

$$
x_{i}^{\prime}=\left\{\begin{array}{cc}
F_{I, o b s}^{-1}\left(F_{I, N A R C C A P}\left(x_{i}\right)\right) & x_{i} \geq \bar{x} \\
0 & x_{i}<\bar{x}
\end{array}\right.
$$

The bias in the NARCCAP temperature series was corrected using a method presented by Samuel et al. [13]. The distribution of the daily NARCCAP temperature was mapped onto the distribution of observed temperature for each of the 12 calendar months. In the case of temperature, correction of frequency distribution and truncation of the empirical distribution of the raw daily NARCCAP temperature data was not performed by using a normal distribution used in this bias correction method to map the temperature distribution. The CDF of the normal temperature distribution was calculated by using Equation 5. The CDF of the daily NARCCAP temperature are mapped to the CDF of the observed data using equation 6 . The corrected NARCCAP temperature $y^{\prime}$ on day $i$ is calculated by Equation 7:

$$
\begin{aligned}
& F(y ; \mu, \alpha,)=\frac{1}{2}\left[1+\operatorname{erf}\left(\frac{y-\mu}{\sqrt{2 \alpha^{2}}}\right)\right] ; y \in \Re \\
& F_{G}(y ; \mu, \alpha)=\int_{0}^{\mathfrak{R}} f(t) d t \\
& y_{i}^{\prime}=F_{T, O B S}^{-1}\left(F_{T, N A R C C A P}\left(y_{i}\right)\right)
\end{aligned}
$$

\section{Description of skill scores}

Two probabilistic verification measures, namely the Brier skill score (BSS) and the rank probability skill score (RPSS), mostly used in the assessment of meteorological forecasts [34-36], were used in this study to assess the quality of bias-corrected climate model simulated precipitation and temperature time series. The BSS and RPSS are based on the Brier score (BS) and the rank probability score (RPS), respectively.

The Brier score [37], which is essentially the mean-square error of probabilistic forecasts, is the most commonly used scalar measure for probability forecasts. It is widely used for dichotomous predictands [35]. This score is also applied to continuous-valued forecast [38]. The continuous valued forecasts are converted into a binary event using a threshold filter which can either be exceeded or not $[38,39]$. In this study, for comparison purpose and consistency, $0.1 \mathrm{~mm} /$ day (threshold to define wet day) for precipitation, and the means of the daily mean temperature of each month for temperature are used as BS thresholds. The Brier score BS is calculated by the equation (8):

$$
B S=\frac{1}{n} \sum_{k=1}^{n}\left(y_{k}-o_{k}\right)^{2}
$$

Where $\mathrm{n}$ represents the number of days, $\mathrm{k}$ is the number of the $\mathrm{n}$ simulation/event pair, $\mathrm{y}_{\mathrm{k}}$ is the simulation probability and $\mathrm{o}_{\mathrm{k}}$ is the observed probability (occurrence and non-occurrence of the event being simulated). $y_{k}$ is derived by the relative frequency of the ensemble members exceeding the chosen threshold. The observations $o_{k}$ are translated similar to the simulated values, i.e., the observation $o_{k}=1$ if the event occurs (if the threshold is exceeded) and $o_{k}=0$ if the event does not occur. The Brier score ranges between 0 and 1 because the observation and probability simulations are bounded by 0 and 1 , a perfect simulation exhibiting $\mathrm{BS}=0$ and less accurate forecasts receive higher Brier score. The Brier skill score (BSS) is computed using equation (9) in order to make comparison between a simulation relative to reference simulation:

$$
B S S=\frac{B S S_{r e f}-B S S}{B S S_{r e f}}
$$

The RPS [35] is a score derived from the Brier score to the multicategory [40]. The RPS is calculated by equation (10):

$$
R P S=\sum_{m=1}^{j}\left(Y_{m}-O_{m}\right)^{2}
$$

Where, $Y_{m}$ is the cumulative probability of the simulation for category $m$ and $O_{m}$ is the cumulative probability of the observation for category $\mathrm{m}$. For a group of $\mathrm{n}$ forecasts, the RPS is the average $(\overline{R P S})$ of the n RPSs:

$$
\overline{R P S}=\frac{1}{n} \sum_{k=1}^{n} R P S_{k}
$$

In this study, the procedure presented by Clark and Hay [41] and Gangopadhyay et al. [42] was used to calculate RPS: At first, the observed time series data are used to differentiate $10(\mathrm{j})$ possible categories (i.e., the minimum value to the $10^{\text {th }}$ percentile, the $10^{\text {th }}$ percentile to the $20^{\text {th }}$ percentile, the $20^{\text {th }}$ percentile to the $30^{\text {th }}$ percentile up to the $90^{\text {th }}$ percentile to the maximum value). These categories were determined separately for each month. In the next step, the number of ensemble member simulation in each category is determined (out of 8 members), and their cumulative probabilities were computed for each simulation-observation pair. Then, in the same way, the observation's cumulative probabilities were computed. All categories below the observation's position are assigned ' 0 ', and all categories equal to and above the observation's position are assigned ' 1 '. The RPS was determined as the squared difference between cumulative probabilities of the observations and simulation, and the summation of squared differences over 10 categories. RPS is zero for a perfect simulation and positive otherwise. The ranked probability skill score (RPSS) was calculated in order to make comparison between a simulation relative to a reference simulation:

$$
R P S S=\frac{\overline{R P S}_{\text {ref }}-\overline{R P S}}{\overline{R P S}_{\text {ref }}}
$$

In this study, NARCCAP simulated raw data was used as the reference simulation to calculate BSS and RPSS. Here, the calculated BSS and RPSS show the percentage improvement of bias-corrected NARCCAP precipitation and daily mean temperature data over the NARCCAP simulated data.

\section{Hydrologic modeling}

HBV hydrologic model: Although hydrological models have been around for quite some time, there is yet to be one exclusive model that can stand apart from the rest and be declared best at modeling all aspects of the hydrologic system' [43]. A hydrologic model HBV [44] was chosen to simulate flows for current and future period at the outlet of the Spencer Creek Watershed. The model was developed at the Swedish Meteorological and Hydrological Institute (SMHI) and its first application dates back to the early 1970s [45]. The HBV model which includes conceptual numerical descriptions of hydrological processes at the catchment scale is best characterized as a semidistributed conceptual hydrologic model. The model is usually run on the daily values of precipitation, temperature and estimates of potential evapotranspiration. Flow observations are used for calibration and 
validation of the model. For most of the applications, the model is run on a daily time step, but it is possible to use shorter time steps. The evapotranspiration values can be used as monthly averaged or daily values. The potential evapotranspiration is calculated using air temperature. The model contains routines for snow accumulation and melt, soil moisture accounting, runoff generation and a routing procedure. The snowmelt routine of the HBV model is a degree-day approach. It is based on air temperature, with a water holding capacity of snow which delays runoff. The soil moisture routine of the model controls runoff formation, accounts for soil field capacity and change in soil moisture storage due to rainfall/snowmelt and evapotranspiration. The excess water from the soil moisture zone transforms to runoff in the response routing. The response function of the model consists of two reservoir-one upper nonlinear, one lower linear, and one transform function. The runoff is computed by adding the contribution from the upper and lower reservoir, and the generated runoff is routed through a transformation function in order to get a proper shape of the hydrograph at the outlet of the watershed.

Model calibration and validation: The process of optimization of model parameters to minimize the difference between model output and observed data is referred to as calibration. A calibrated model needs to be verified for ensuring that the optimized parameters are a good representation of the physical behavior of the catchment. The parameters of the HBV model need to be calibrated in order to provide model output that closely resembles observed data as it is a conceptual model. The HBV manual [46] recommends using at least 10 years of data for the calibration period. It is also recommended to use $75 \%$ of total data for model calibration and $25 \%$ of data for model validation.
The first 22 years of data (from 1985 to 2006) were used to calibrate the hydrologic model and the last 8 years of data (2007-2014) were used to validate the model. The calibration and validation of the hydrologic model were carried out using the observed and simulated flow hydrograph of daily time step at the outlet (Spencer Creek at Dundas hydrometric station) of the watershed. Following the recommendation of the HBV manual during calibration, the evaluation of the results was mainly done by comparing the explained variance/ Nash and Sutcliffe coefficient $\mathrm{R}^{2}$ [47], and visually inspecting and comparing the simulated and observed hydrographs. The Nash and Sutcliffe coefficient is the variance around the mean explained by the model. The optimum value of the Nash and Sutcliffe coefficient is one (1), and a value less than 0.7 represent poor performance [48]. The model calibration and validation results of the Spencer Creek watershed model show a good performance according to the Nash and Sutcliffe coefficient of 0.76 for the calibration period and 0.75 for the validation period. The equation used to calculate the Nash and Sutcliffe coefficient $\left(\mathrm{R}^{2}\right)$ is as follows:

$$
\operatorname{NASH}\left(\mathrm{R}^{2}\right)=1-\frac{\sum_{i}^{N}\left(\mathrm{y}_{\mathrm{i}}-\mathrm{y}_{\mathrm{i}}^{\prime}\right)^{2}}{\sum_{i=1}^{N}\left(\mathrm{y}_{\mathrm{i}}-\mathrm{y}_{\text {mean }}\right)^{2}}
$$

where, $y_{i}$ is the observed streamflow at time step $i, y_{i}^{\prime}$ is simulated streamflow at time step $\mathrm{i}, \mathrm{y}_{\text {mean }}$ is the mean of observed streamflow, and $\mathrm{N}$ is the number of data points.

Figures 2 and 3 demonstrate observed flow and simulated flow from the hydrologic model for two years of both calibration and validation period, respectively.

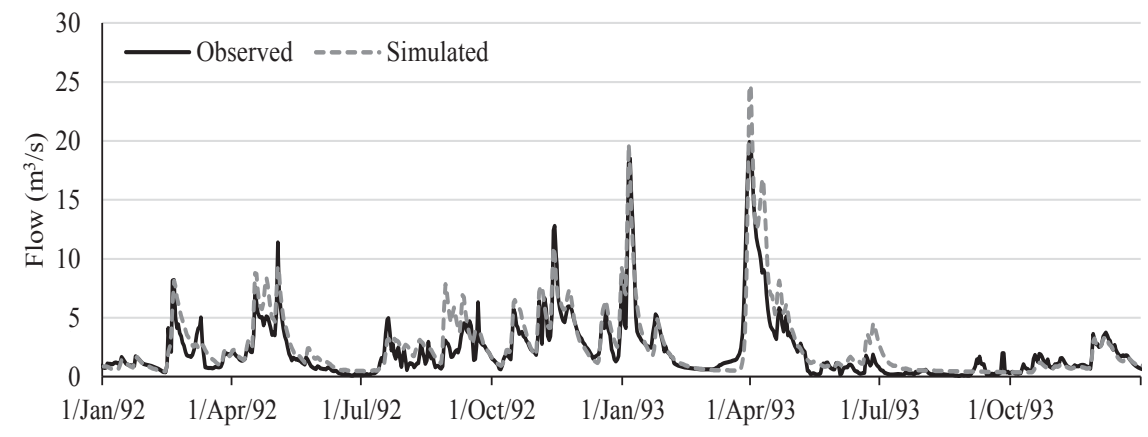

Figure 2: Observed and simulated flows at Dundas station in the calibration period of 1992-1993.

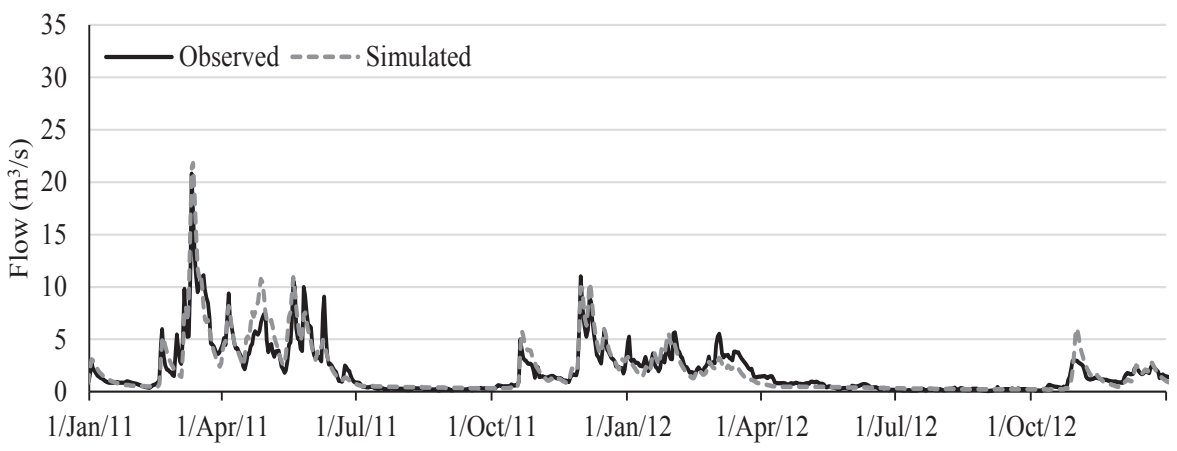

Figure 3: Observed and simulated flows at Dundas station in the validation period of 2011-2012. 
Page 6 of 12

Hydrologic simulation: The calibrated HBV model was used to simulate flows at the outlet and evapotranspiration from the watershed at a daily time step for both current (1971-2000) and future (2041-2070) period. The bias-corrected daily total precipitation and daily mean temperature from eight RCM+GCM pairs for current (1971-2000) and future (2041-2070) period were used as input in the watershed model for hydrologic simulation.

\section{Results and Discussion}

\section{Evaluation of bias-corrected data}

Bias correction was applied to raw NARCCAP daily precipitation and mean temperature (calculated from NARCCAP daily maximum and minimum temperature) both for current (1971-2000) and future (2041-2070) period using the method described in Bias Correction Section. The improvement in bias-corrected NARCCAP projections was assessed using skill score BSS and RPSS described in Description of Skill Scores section, and the BSS and RPSS show the percentage improvement in this study. The BS and RPS were calculated for raw and bias-corrected NARCCAP eight RCM+GCM pair's data for the current period. The scores and skill scores calculated for two meteorological stations namely Hamilton Airport and Hamilton RBG are presented in Tables 2-5. The skill scores represent the improvement of bias-corrected NARCCAP data over raw NARCCAP data produced by eight $\mathrm{RCM}+\mathrm{GCM}$ pairs. The calculated skill scores revealed an overall improvement in both precipitation and temperature at both stations when bias correction is made. In the case

\begin{tabular}{|c|c|c|c|c|c|c|}
\hline \multirow{2}{*}{ Month } & BS & BS & \multirow{2}{*}{ BSS (\%) } & RPS & RPS & \multirow{2}{*}{ RPSS (\%) } \\
\cline { 2 - 3 } & Raw & Bias-Cor & & Raw & Bias-Cor & \\
\hline Jan & 0.29 & 0.28 & 3.4 & 1.1 & 1.09 & 0.9 \\
\hline Feb & 0.32 & 0.29 & 9.4 & 1.14 & 1.12 & 1.8 \\
\hline Mar & 0.32 & 0.29 & 9.4 & 0.81 & 0.8 & 1.2 \\
\hline Apr & 0.31 & 0.28 & 9.7 & 0.87 & 0.82 & 5.7 \\
\hline May & 0.34 & 0.28 & 17.6 & 0.57 & 0.54 & 5.3 \\
\hline Jun & 0.33 & 0.27 & 18.2 & 0.57 & 0.53 & 7 \\
\hline Jul & 0.32 & 0.26 & 18.8 & 0.58 & 0.53 & 8.6 \\
\hline Aug & 0.3 & 0.26 & 13.3 & 0.55 & 0.53 & 3.6 \\
\hline Sep & 0.29 & 0.27 & 6.9 & 0.54 & 0.54 & 0 \\
\hline Oct & 0.31 & 0.28 & 9.7 & 0.86 & 0.84 & 2.3 \\
\hline Nov & 0.32 & 0.29 & 9.4 & 0.83 & 0.81 & 2.4 \\
\hline Dec & 0.33 & 0.29 & 12.1 & 1.15 & 1.13 & 1.7 \\
\hline
\end{tabular}

Table 2: Skill score of bias-corrected precipitation at Hamilton Airport.

\begin{tabular}{|c|c|c|c|c|c|c|}
\hline \multirow{2}{*}{ Month } & BS & BS & \multirow{2}{*}{ BSS (\%) } & RPS & RPS & \multirow{2}{*}{ RPSS (\%) } \\
\cline { 2 - 3 } & Raw & Bias-Cor & & Raw & Bias-Cor & \\
\hline Jan & 0.32 & 0.29 & 9.4 & 0.84 & 0.83 & 1.2 \\
\hline Feb & 0.33 & 0.29 & 12.1 & 0.85 & 0.82 & 3.5 \\
\hline Mar & 0.34 & 0.28 & 17.6 & 0.55 & 0.55 & 0 \\
\hline Apr & 0.32 & 0.28 & 12.5 & 0.89 & 0.83 & 6.7 \\
\hline May & 0.34 & 0.27 & 20.6 & 0.55 & 0.53 & 3.6 \\
\hline Jun & 0.33 & 0.26 & 21.2 & 0.56 & 0.52 & 7.1 \\
\hline Jul & 0.32 & 0.26 & 18.8 & 0.56 & 0.53 & 5.4 \\
\hline Aug & 0.3 & 0.27 & 10 & 0.54 & 0.53 & 1.9 \\
\hline Sep & 0.3 & 0.28 & 6.7 & 0.55 & 0.55 & 0 \\
\hline Oct & 0.31 & 0.27 & 12.9 & 0.57 & 0.55 & 3.5 \\
\hline Nov & 0.33 & 0.29 & 12.1 & 0.84 & 0.83 & 1.2 \\
\hline Dec & 0.34 & 0.29 & 14.7 & 0.85 & 0.84 & 1.2 \\
\hline \multicolumn{2}{|l|}{ Table 3: Skill score of bias-corrected precipitation at Hamilton RBG. } \\
\hline
\end{tabular}

\begin{tabular}{|c|c|c|c|c|c|c|}
\hline \multirow{2}{*}{ Month } & BS & BS & \multirow{2}{*}{ BSS (\%) } & RPS & RPS & \multirow{2}{*}{ RPSS (\%) } \\
\cline { 2 - 6 } & Raw & Bias-Cor & & Raw & Bias-Cor & \\
\hline Jan & 0.31 & 0.3 & 3.2 & 1.97 & 1.96 & 0.5 \\
\hline Feb & 0.29 & 0.28 & 3.4 & 1.91 & 1.89 & 1 \\
\hline Mar & 0.26 & 0.25 & 3.8 & 1.76 & 1.73 & 1.7 \\
\hline Apr & 0.26 & 0.25 & 3.8 & 1.75 & 1.73 & 1.1 \\
\hline May & 0.25 & 0.24 & 4 & 1.68 & 1.62 & 3.6 \\
\hline Jun & 0.28 & 0.25 & 10.7 & 1.87 & 1.7 & 9.1 \\
\hline Jul & 0.29 & 0.28 & 3.4 & 2.03 & 1.93 & 4.9 \\
\hline Aug & 0.29 & 0.28 & 3.4 & 2.03 & 1.92 & 5.4 \\
\hline Sep & 0.27 & 0.26 & 3.7 & 1.85 & 1.76 & 4.9 \\
\hline Oct & 0.27 & 0.27 & 0 & 1.86 & 1.81 & 2.7 \\
\hline Nov & 0.27 & 0.27 & 0 & 1.84 & 1.8 & 2.2 \\
\hline Dec & 0.3 & 0.3 & 0 & 1.91 & 1.9 & 0.5 \\
\hline
\end{tabular}

Table 4: Skill score of bias-corrected temperature at Hamilton Airport.

\begin{tabular}{|c|c|c|c|c|c|c|}
\hline \multirow{2}{*}{ Month } & BS & BS & \multirow{2}{*}{ BSS (\%) } & RPS & RPS & \multirow{2}{*}{ RPSS (\%) } \\
\cline { 2 - 6 } & Raw & Bias-Cor & & Raw & Bias-Cor & \\
\hline Jan & 0.33 & 0.3 & 9.1 & 2.11 & 1.96 & 7.1 \\
\hline Feb & 0.3 & 0.28 & 6.7 & 2.09 & 1.88 & 10 \\
\hline Mar & 0.28 & 0.26 & 7.1 & 1.84 & 1.76 & 4.3 \\
\hline Apr & 0.26 & 0.25 & 3.8 & 1.8 & 1.74 & 3.3 \\
\hline May & 0.25 & 0.25 & 0 & 1.81 & 1.65 & 8.8 \\
\hline Jun & 0.31 & 0.26 & 16.1 & 2.06 & 1.72 & 16.5 \\
\hline Jul & 0.32 & 0.3 & 6.3 & 2.29 & 1.96 & 14.4 \\
\hline Aug & 0.3 & 0.28 & 6.7 & 2.12 & 1.9 & 10.4 \\
\hline Sep & 0.29 & 0.26 & 10.3 & 2.03 & 1.77 & 12.8 \\
\hline Oct & 0.27 & 0.26 & 3.7 & 1.95 & 1.78 & 8.7 \\
\hline Nov & 0.3 & 0.27 & 10 & 2.07 & 1.81 & 12.6 \\
\hline Dec & 0.33 & 0.29 & 12.1 & 2.12 & 1.92 & 9.4 \\
\hline
\end{tabular}

Table 5: Skill score of bias-corrected temperature at Hamilton RBG.

of precipitation, the BS values do not show a seasonal pattern in skill, but the RPS values show that overall skill in other seasons is better than the skill in winter months. Both BSS and RPSS results shown in Table 2 indicate that improvement is higher in the late spring and summer months than others months, and the highest improvement is shown in the month of July with BSS and RPSS values of $18.8 \%$ and $8.6 \%$, respectively. A similar seasonal pattern in the improvement of bias-corrected precipitation at Hamilton RBG is shown in Table 3 , and it also shows that the highest improvement is in the month of June with BSS and RPSS values of $21.2 \%$ and $7.1 \%$, respectively. Results in Tables 2 and 3 show that the improvement presented by RPSS is higher when the RPS of raw NARCCAP precipitation is lower in general. For example, RPS values for raw NARCCAP precipitation at Hamilton Airport are 0.57 and 1.15 in the month of June and December, respectively, and the corresponding RPSS values are $7 \%$ and $1.7 \%$. Both BSS and RPSS values shown in Tables 4 and 5 indicate that there is a significant improvement in quality in bias-corrected daily mean temperature for both meteorological stations, and the improvement is slightly better for Hamilton RBG station than Hamilton Airport station. Both BSS and RPSS values also show that the improvement in the quality of bias-corrected daily mean temperature is highest in the month of June for both stations. The BSS and RPSS values are $10.7 \%$ and $9.1 \%$ in the month of June for Hamilton Airport, and these values are $16.1 \%$ and $16.5 \%$ for Hamilton RBG station. The RPSS values show that the overall improvement in the quality of bias-corrected temperature is better in the summer months than other seasons. 


\section{Monthly average changes in climate variables and flows}

The bias-corrected NARCCAP precipitation and daily mean temperature time series over thirty years for both current (1971-2000) and future (2041-2070) periods were analyzed to show the changes under future climate condition. The hydrologic model simulated actual evapotranspiration for the same periods was also analyzed to show any changes. The monthly average values for these variables were calculated to get insight about how the changes are distributed seasonally. Here, the monthly average values were calculated from the average of eight $\mathrm{RCM}+\mathrm{GCM}$ pairs. The calculated monthly average precipitation and daily mean temperature for Hamilton Airport and Hamilton RBG stations are presented in Figures 4-7. Figure 4 and 5 shows that precipitation increases significantly for the most part of the year except the summer months including September. The increase in precipitation under future climate at Hamilton Airport station varies between $3 \%$ and $17 \%$, and the lowest and highest increase are in a fall month, October and a winter month, January, respectively. A similar increase in future precipitation is shown at Hamilton RBG as the lowest increase of $6 \%$ in a fall month-November and the higher increase of $16-17 \%$ in two winter months, December and January. The increase in precipitation during March, April and May are similar as shown in Figures 4 and 5 . The decrease in precipitation will be highest (10-11\%) in the summer month of July for both Hamilton and Hamilton RBG station, and the decrease of precipitation in June is insignificant for both meteorological stations. Figures 4 and 5 also show that the higher

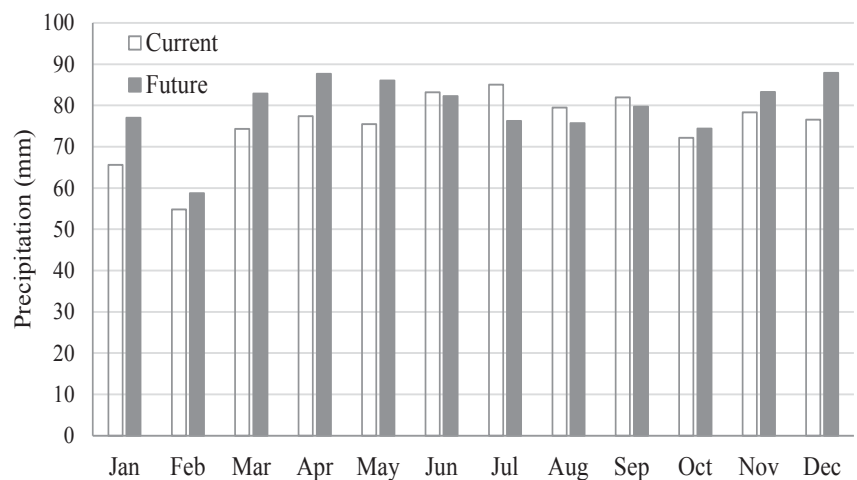

Figure 4: Bias-corrected current and future climate model simulated precipitation at Hamilton Airport.

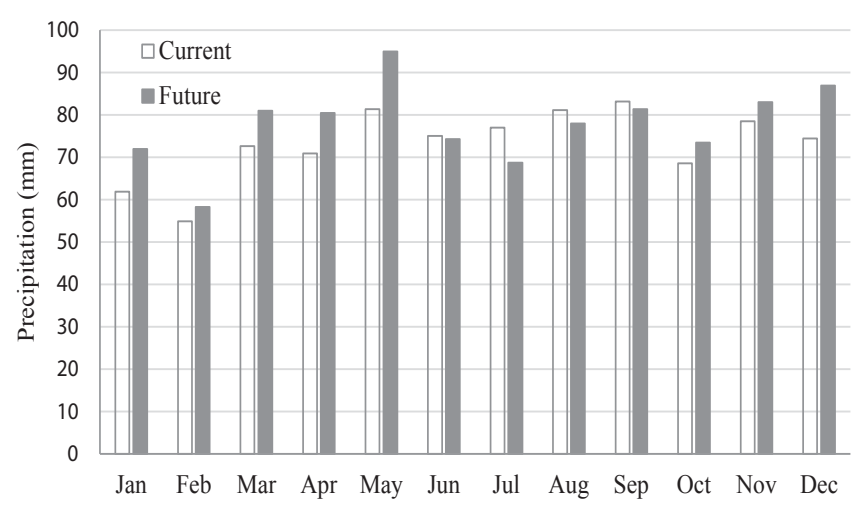

Figure 5: Bias-corrected current and future climate model simulated precipitation at Hamilton RBG.

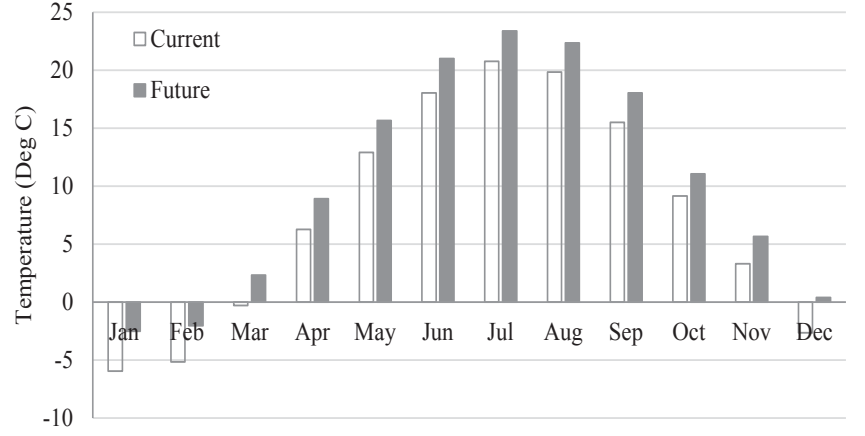

Figure 6: Bias-corrected current and future climate model simulated mean temperature at Hamilton Airport.

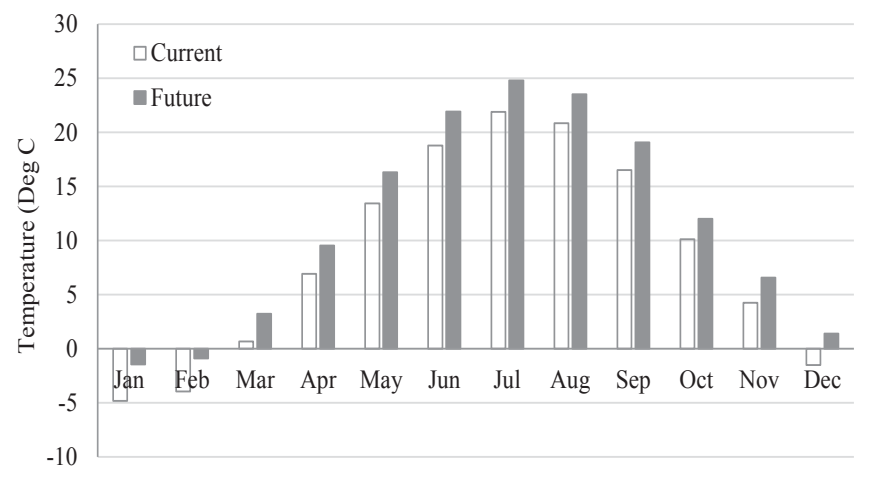

Figure 7: Bias-corrected current and future climate model simulated mean temperature at Hamilton RBG.

amounts of monthly average precipitation in the future are in April and December at Hamilton Airport, and in May and December at Hamilton RBG station. The precipitation projection of average RCMs shows a clear signal of seasonal distribution of change in the precipitation regime. From Figures 6 and 7, it appears that the daily mean temperature will increase in all months at both meteorological stations. Figures 6 and 7 show that the highest and lowest daily mean temperatures are in July and January, respectively at both stations. The increase in temperature under future climate varies between $1.91^{\circ} \mathrm{C}$ and $3.44^{\circ} \mathrm{C}$ at Hamilton Airport station and $1.9^{\circ} \mathrm{C}$ and $3.37^{\circ} \mathrm{C}$ at Hamilton RBG. The lowest and highest increases are in October and January, respectively. These increases of temperature are close to the increases revealed by Sultana and Coulibaly [4]. A higher increase in the summer month of June than other months in spring, summer and fall are also shown in the figures. Overall, the increase in daily mean temperature in all winter months is higher than other seasons. The temperature projection of average RCMs shows a clear signal of seasonal distribution of change in the temperature. The actual evapotranspiration on daily time step was simulated by the hydrologic model for current and future periods, and the monthly average values of the average of eight RCM+GCM pairs are presented in Figure 8. It can be seen from Figure 8 that the actual evapotranspiration in the future is higher than the current period in all months except in July and August. Increase in evapotranspiration in July is insignificant because of an insignificant decrease in monthly average precipitation, although there is a significant increase in temperature $\left(2.97^{\circ} \mathrm{C}\right.$ and $3.16^{\circ} \mathrm{C}$ at Hamilton Airport and Hamilton $\mathrm{RBG}$ ) in future. The higher decrease in precipitation and lower increase in temperature in other summer months, July and August than in June 
resulted in about $10 \%$ decrease in evapotranspiration. Figure 8 also shows a small amount of evapotranspiration in the winter. Although the actual evapotranspiration is very low in the winter months, the percentage increase is higher in the winter than in other seasons because

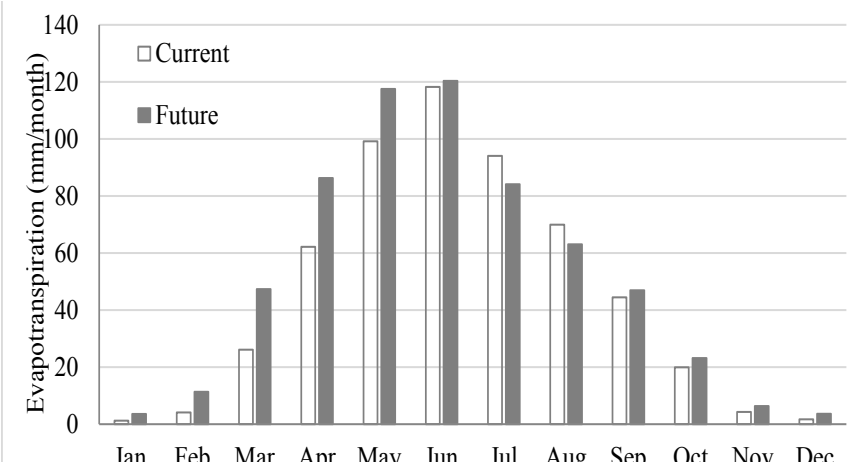

Figure 8: Model simulated monthly evapotranspiration at the watershed.

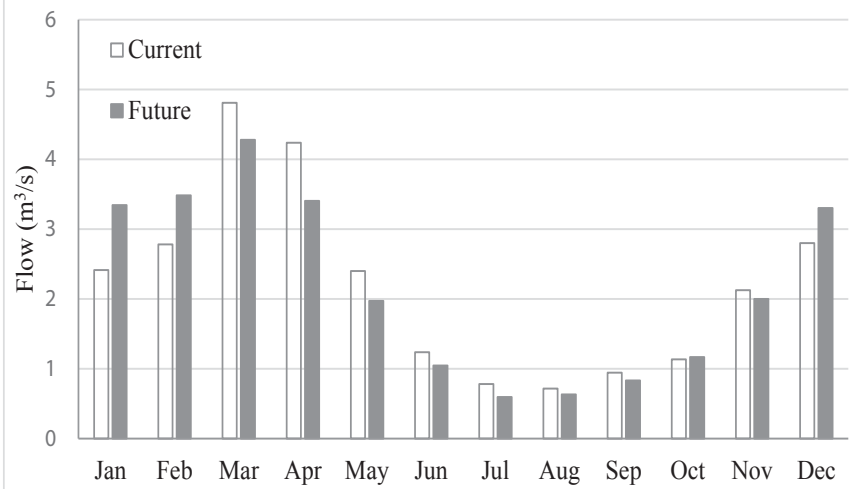

Figure 9: Model simulated average monthly flow at the Spencer Creek at Dundas station. of a higher increase in temperature and increase in precipitation. In can be seen from Figure 8 that the total increase in evapotranspiration in each month $(21 \mathrm{~mm}, 24 \mathrm{~mm}$ and $18 \mathrm{~mm}$ in March, April and May, respectively) of spring is much higher than in other seasons.

Figure 9 presents the monthly average flows of the average of eight $\mathrm{RCM}+\mathrm{GCM}$ pairs for both current and future periods. It can be seen from Figure 9 that the monthly flows increase in the winter and decrease in other seasons except an insignificant increase $\left(0.03 \mathrm{~m}^{3} / \mathrm{s}\right)$ in October. The seasonal distribution of future flow is similar to the findings presented by Grillakis et al. [3]. The increase in flow in December, January and February are $17.9 \%$ (or $0.50 \mathrm{~m}^{3} / \mathrm{s}$ ), 38.5\% (or $0.93 \mathrm{~m}^{3} / \mathrm{s}$ ) and $25.3 \%\left(0.70 \mathrm{~m}^{3} / \mathrm{s}\right)$, respectively. The decrease in flows in future varies between $6 \%$ (or $0.13 \mathrm{~m}^{3} / \mathrm{s}$ ) and $24.1 \%$ (or $0.19 \mathrm{~m}^{3} / \mathrm{s}$ ), and the lowest and the highest decrease are in November and in July, however the highest decrease in terms of flow magnitude is in April, where the change is $0.83 \mathrm{~m}^{3} / \mathrm{s}$ (or 19.7\%). The effect of a change in precipitation, temperature, and evapotranspiration for the resultant change in future flow is complex. The effect of a change in evapotranspiration on flow in the winter months is small as the monthly average evapotranspiration is very small in these months. The higher increase in flows in winter months could be attributed to the increase in both winter month's precipitation and temperature in future. The warmer winter temperature in future will increase the winter snowmelt, and will result in the decrease of snowpack for annual basis and termination of snowmelt in the earlier in the spring. Despite the increase in the future precipitation in the spring, the flow will be decreased in the spring because thinner snowpack left to be melted and high evapotranspiration increase in this season. The decrease in flows in the summer is caused by the decrease in precipitation in future, and a comparatively small decrease in the fall could be attributed to the increase of evapotranspiration.

\section{Yearly average changes in climate variables and flows}

The difference between the current and future climate variables and flows were analysed, and the annual average of precipitation, daily mean temperature, and the hydrologic model simulated actual evapotranspiration and flows are presented in Table 6. It can be seen from Table 6 that six RCM+GCM pairs out of eight pairs projected

\begin{tabular}{|c|c|c|c|c|c|c|c|c|c|c|c|}
\hline $\begin{array}{l}\text { Station/ } \\
\text { Watershed }\end{array}$ & Element & Period & $\begin{array}{l}\text { Crcm } \\
\text { Ccsm }\end{array}$ & $\begin{array}{l}\text { Crcm } \\
\text { Cgcm3 }\end{array}$ & $\begin{array}{c}\text { Hrm3 } \\
\text { Gfdl }\end{array}$ & $\begin{array}{c}\text { Hrm3 } \\
\text { Hadcm3 }\end{array}$ & $\begin{array}{c}\mathrm{Rcm} 3 \\
\mathrm{Cgcm} 3\end{array}$ & $\begin{array}{r}\text { Rcm3 } \\
\text { Gfdl }\end{array}$ & $\begin{array}{l}\text { Wrfg } \\
\text { Ccsm }\end{array}$ & $\begin{array}{l}\text { Wrfg } \\
\text { Cgcm3 }\end{array}$ & Average \\
\hline Hamilton & $\mathrm{P}$ (mm/day) & Current & 2.44 & 2.46 & 2.48 & 2.48 & 2.46 & 2.45 & 2.52 & 2.51 & 2.47 \\
\hline \multirow[t]{5}{*}{ Airport } & $\mathrm{P}$ (mm/day) & Future & 2.47 & 2.67 & 2.35 & 2.74 & 2.64 & 2.69 & 2.45 & 2.84 & 2.57 \\
\hline & $\%$ & Change & 1 & 8.7 & -5.2 & 10.6 & 7.3 & 9.6 & -2.8 & 13 & 4.1 \\
\hline & $\mathrm{T}\left({ }^{\circ} \mathrm{C}\right)$ & Current & 7.7 & 7.7 & 7.7 & 7.7 & 7.7 & 7.7 & 7.7 & 7.7 & 7.7 \\
\hline & $\mathrm{T}\left({ }^{\circ} \mathrm{C}\right)$ & Future & 10.61 & 10.81 & 11.11 & 10.31 & 10.28 & 10.25 & 9.98 & 9.99 & 10.48 \\
\hline & ${ }^{\circ} \mathrm{C}$ & Change & 2.9 & 3.11 & 3.4 & 2.61 & 2.58 & 2.54 & 2.27 & 2.28 & 2.77 \\
\hline Hamilton & $\mathrm{P}$ (mm/day) & Current & 2.37 & 2.38 & 2.43 & 2.46 & 2.37 & 2.37 & 2.45 & 2.43 & 2.4 \\
\hline \multirow[t]{5}{*}{ RBG } & $\mathrm{P}$ (mm/day) & Future & 2.39 & 2.6 & 2.34 & 2.62 & 2.62 & 2.68 & 2.4 & 2.77 & 2.52 \\
\hline & $\%$ & Change & 0.8 & 9.2 & -3.7 & 6.7 & 10.3 & 13 & -1.8 & 14 & 4.9 \\
\hline & $\mathrm{T}\left({ }^{\circ} \mathrm{C}\right)$ & Current & 8.65 & 8.65 & 8.65 & 8.65 & 8.65 & 8.65 & 8.65 & 8.65 & 8.65 \\
\hline & $\mathrm{T}\left({ }^{\circ} \mathrm{C}\right)$ & Future & 11.53 & 11.73 & 12.25 & 11.36 & 11.21 & 11.21 & 10.92 & 10.92 & 11.46 \\
\hline & ${ }^{\circ} \mathrm{C}$ & Change & 2.87 & 3.08 & 3.59 & 2.71 & 2.56 & 2.56 & 2.27 & 2.26 & 2.8 \\
\hline \multirow[t]{3}{*}{ Spencer } & $\mathrm{E}$ (mm/day) & Current & 1.6 & 1.74 & 1.59 & 1.74 & 1.71 & 1.73 & 1.63 & 1.71 & 1.68 \\
\hline & $\mathrm{E}(\mathrm{mm} /$ day $)$ & Future & 1.47 & 1.48 & 1.52 & 1.51 & 1.5 & 1.51 & 1.49 & 1.47 & 1.49 \\
\hline & $\%$ & Change & 8.7 & 17.6 & 4.8 & 14.7 & 14.4 & 14.2 & 9.6 & 16.3 & 12.51 \\
\hline \multirow[t]{3}{*}{ Dundas } & $\mathrm{Q}\left(\mathrm{m}^{3} / \mathrm{s}\right)$ & Current & 2 & 2.19 & 1.87 & 2.28 & 2.2 & 2.32 & 1.96 & 2.51 & 1.92 \\
\hline & $\mathrm{Q}\left(\mathrm{m}^{3} / \mathrm{s}\right)$ & Future & 2.16 & 2.18 & 2.19 & 2.23 & 2.13 & 2.11 & 2.28 & 2.28 & 1.91 \\
\hline & $\%$ & Change & -7.3 & 0.1 & -14.7 & 1.9 & 3.3 & 10 & -13.8 & 10 & 0.5 \\
\hline
\end{tabular}

Table 6: Changes in annual average precipitation, daily mean temperature, evapotranspiration and flow. 
Citation: Ahmed S, Tsanis I (2016) Watershed Response to Bias-Corrected Improved Skilled Precipitation and Temperature under Future Climate - A Case Study on Spencer Creek Watershed, Ontario, Canada. Hydrol Current Res 7: 246. doi:10.4172/2157-7587.1000246

Page 9 of 12

an increase in precipitation with the highest increase projected by WRFG+CGCM3 model at $13 \%$ and $14 \%$ for Hamilton Airport and Hamilton RBG, respectively. It is worth mentioning that all the $\mathrm{RCM}+\mathrm{GCM}$ pairs show an increase in the annual average of daily mean temperature. The increase in temperature in future varies between $2.27^{\circ} \mathrm{C}$ and $3.4^{\circ} \mathrm{C}$ at Hamilton Airport and between $2.26^{\circ} \mathrm{C}$ and $3.59^{\circ} \mathrm{C}$ at Hamilton RBG. The greatest change in terms of temperature increase is projected by HRM3+GFDL models and the most conservative change is projected by WRFG+CCSM and WRFG+CGCM3 models for Hamilton Airport and Hamilton RBG, respectively. The CRCM model projected temperature change is higher than other models except the HRM3+GFDL, and the WRFG model projected temperature increase is lower than the other models. It is notable that the annual average evapotranspiration under future climate compared to current climate will increase for all the RCM+GCM pairs. Table 6 shows that the annual average flows at the Spencer Creek at Dundas hydrometric station will be increased in the case of five $\mathrm{RCM}+\mathrm{GCM}$ pairs out of eight pairs, and the higher increase (10\%) is exhibited by RCM3+GFDL and WRFG+CGCM3 model while the highest decrease (14.7\%) is exhibited by HRM3+GFDL model. Overall, the decrease in flows is also shown by one GCM (CCSM) with two RCMs. Averages of eight RCM+GCM pairs show an increase for all climate variables and a small increase of annual average flow in future. In the case of annual average flows, a difference from the study done by Grillakis et al. [3] is noticed, and the difference resulted due to the use of a different period of data for bias correction and flow comparison for current and future period, and the use of a different number of RCM+GCM pairs. Taking into account the future increase in annual average flow, analysis of flow duration were performed to get insight into how the flow regime will be changed under future climate condition.

\section{High and low flows}

Figures 10 and 11 present the flow duration curves created using simulated flows at the Spencer Creek at Dundas hydrometric station for the current (1971-2000) and future period (2041-2070). The simulated current and future flows were obtained by inputting the bias-corrected NARCCAP's eight RCM+GCM pair's precipitation and temperatures into a calibrated hydrologic model. Figure 10 presents the flow duration curves for four RCM+GCM pairs, and Figure 11 presents the flow duration curve for the other four RCM+GCM pairs. For better visualization of the difference between flow duration curves, the maximum value on the ordinates is set to $6 \mathrm{~m}^{3} / \mathrm{s}$, and the eight
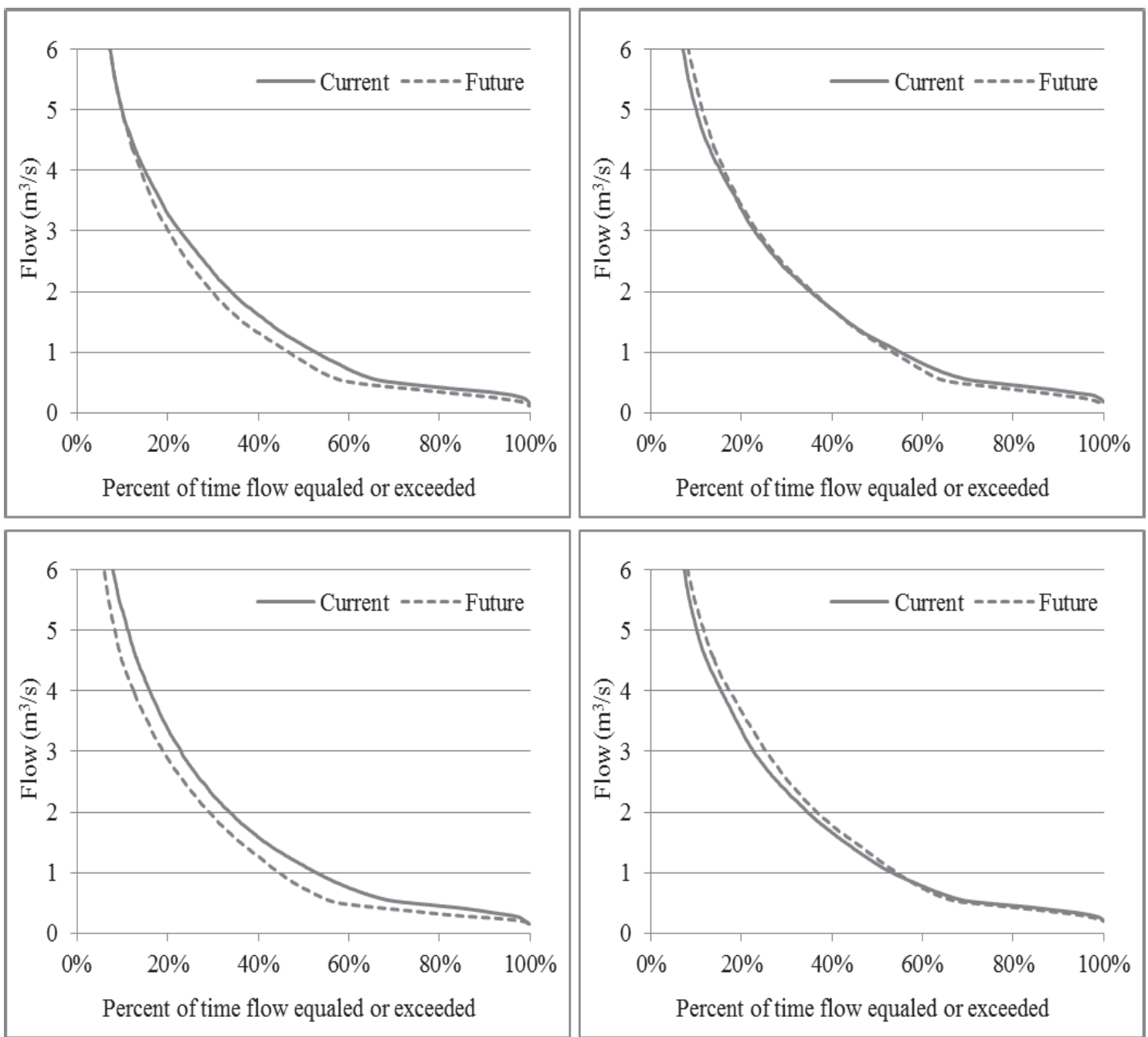

Figure 10: Flow duration curves for the Spencer Creek watershed (top left, top right, bottom left and bottom right represent CrcmCcsm, CrcmCgcm3, Hrm3Gfdl and Hrm3Hadcm3, respectively). 

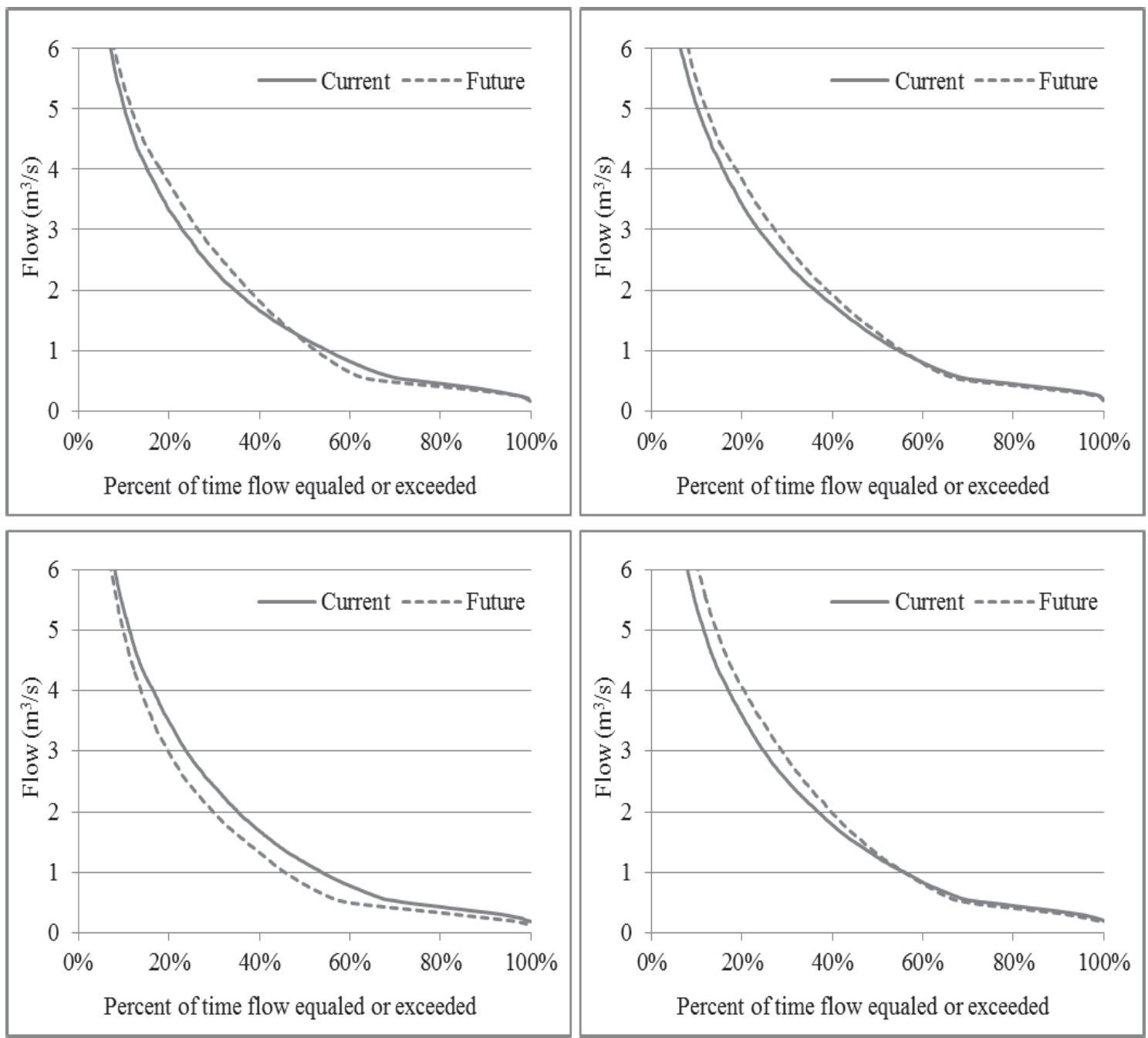

Figure 11: Flow duration curves for the Spencer Creek watershed (top left, top right, bottom left and bottom right represent Rcm3Cgcm3, Rcm3Gfdl, WrfgCcsm and WrfgCgcm3, respectively).

$\mathrm{RCM}+\mathrm{GCM}$ results are presented in two Figures. For every time series of daily flow data, the exceedance probability of each flow was calculated, and flow duration curves were produced by plotting discharge on the ordinate and exceedance probability on the abscissa. The large difference between the highest and the lowest flow values as shown in the flow duration curves in Figures 10 and 11 reveals that the watershed has a relatively low flow during the dry periods, but responds to extreme precipitation event with a relatively high flow. Two flow statistics, $Q_{95}$ and $\mathrm{Q}_{10}$, were used to compare the flow duration curves for current and future periods. $\mathrm{Q}_{95}$ and $\mathrm{Q}_{10}$ are the flow values that are equaled or exceeded $95 \%$ and $10 \%$ of the time, respectively. $Q_{95}$ and $Q_{10}$ are used for analysis of low flow and high flow, respectively [49]. As illustrated in Figures 10 and 11, the low flow decreased for all RCM+GCM pairs with the highest decrease $(28.6 \%)$ exhibited by WRFG+CCSM model and lowest decrease (3.4\%) exhibited by RCM3+CGCM3, and the calculated average low flow value for eight models indicates a decrease by $16.7 \%$ under future climate condition. It can be seen from Figures 10 and 11 that the high flow will increase for five RCM+GCM pairs $(8.2 \%$, $7.3 \%, 6.9 \%, 8.1 \%$ and $13.2 \%$ for CRCM+CGCM3, HRM3+HADCM3, RCM3+CGCM3, RCM3+GFDL and WRFG+CGCM3, respectively), and decrease for other three RCM+GCM pairs $(0.4 \%, 16.1 \%$ and $7.1 \%$ for CRCM+CCSM, HRM3+GFDL and WRFG+CCSM, respectively), and the calculated average high flow value for eight models indicates an increase by $2.4 \%$ under future climate condition. The maximum increase in high flow is obtained for WRFG+CGCM3 model, for which the increase of annual average precipitation is the highest, and a maximum decrease of high flow is obtained for HRM3+GFDL model, for which the decrease of annual average precipitation and increase of mean temperature is the highest. Taking into account that the increase in precipitation is consistent, and the high flow is mainly attributed to the precipitation amount, flow duration curves were constructed for the average of five RCM+GCM pairs (CRCM+CGCM3, HRM3+HADCM3, RCM3+CGCM3, RCM3+GFDL and WRFG+CGCM3), and shown in Figure 12. It is shown in the figure that the high flow will increase, and low flow will decrease significantly. The $\mathrm{Q}_{95}$ is obtained as $0.31 \mathrm{~m}^{3} / \mathrm{s}$ and $0.27 \mathrm{~m}^{3} / \mathrm{s}$ for current and future climate that resulted in $12.9 \%$ decrease in low flow, and $\mathrm{Q}_{10}$ is obtained as $5.11 \mathrm{~m}^{3} / \mathrm{s}$ and $5.56 \mathrm{~m}^{3} / \mathrm{s}$ for current and future climate that resulted in $8.8 \%$ increase in high flow.

\section{Conclusions}

The potential impact of climate change on the hydrology of Spencer Creek watershed was analyzed based on the NARCCAP provided 


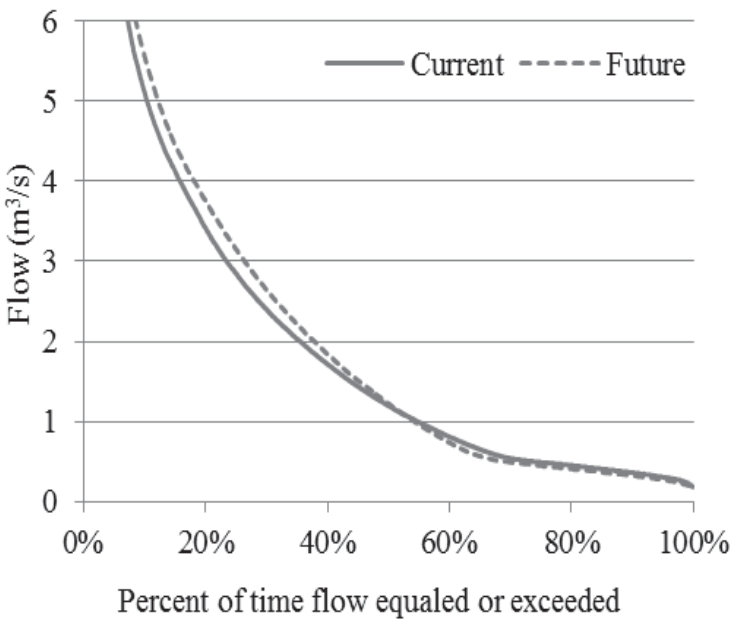

Figure 12: Flow duration curves of average of five RCM+GCM pairs for the Spencer Creek watershed.

eight RCM+GCM pair's precipitation and temperature projections and simulations by using HBV hydrologic model for the current (19712000) and future (2041-2070) period.

The NARCCAP meteorological projections were bias corrected to get more realistic simulations from the hydrologic model. An overall improvement for the quality of NARCCAP precipitation and temperature simulations at both Hamilton Airport and Hamilton RBG meteorological stations was achieved when bias correction was applied. Both BSS and RPSS indicate that improvement is high in the late spring and summer months in the case of precipitation. The overall improvement in the quality of bias-corrected temperature is the best for summer months as revealed by RPSS with the highest improvement obtained in June as revealed by both BSS and RPSS.

The climate variables and flow were analyzed on monthly and annually to get insight into the seasonal and overall change under future climate compared to the current climate. Finally, high and low flow were analyzed by using the flow duration curves for eight RCM+GCM pair's data and average of the RCM+GCM pair's data. The RCM+GCM average shows that the precipitation will increase in the fall, winter and spring and decrease in the summer, the temperature will increase in all months, actual evapotranspiration will increase in all months except July and August, and the flow will increase in the winter and decrease in the other seasons. The RCM+GCM averages also show a significant increase in all climate variables and a small increase in annual average flow. The small increase in annual average flow could be attributed to the very high decrease in low flow despite an increase in high flow. The WRFG+CGCM3 model projected the greatest increase in high flow by $13.2 \%$ and the WRFG+CCSM model projected the highest decrease in low flow by $28.6 \%$. The averages of eight $\mathrm{RCM}+\mathrm{GCM}$ pairs show an increase of high flow by $2.4 \%$ and a decrease of low flow by $16.7 \%$ and the average of five RCM+GCM pairs (precipitation projected by this model are consistent) revealed an increase of high flow by $8.8 \%$ and a decrease of low flow by $12.9 \%$. The changes in winter and spring flow will influence the water management at watershed scale. The authorities have to adopt new strategies to manage higher winter and lower spring flow and higher uncertainty in flows for the watershed management infrastructures.

\section{Acknowledgements}

We wish to thank the North American Regional Climate Change Assessment
Program (NARCCAP) for providing the data used in this paper. The authors gratefully acknowledged Hamilton Region Conservation Authority, Water Survey Canada and Environment Canada for providing data for the study area. This study was supported by the Natural Sciences and Engineering Research Council (NSERC) of Canada in the form of discovery grant (RGPIN04808-14).

\section{References}

1. IPCC (2014) Climate Change 2014: Synthesis Report. Contribution of Working Groups I, II and III to the Fifth Assessment Report of the Intergovernmental Panel on Climate Change. Core Writing Team, Pachauri PK, Meyer LA (eds.) IPCC, Geneva, Switzerland, p: 151

2. Islam Z, Gan TY (2014) Effect of climate change on the surface-water management of South Saskatchewan river basin. Journal of Water Resources Planning and Management 140: 332-342.

3. Grillakis MG, Koutroulis AG, Tsanis IK (2011) Climate change impact on the hydrology of Spencer creek watershed in Southern Ontario, Canada. Journal of Hydrology 409: 1-19.

4. Sultana Z, Coulibaly P (2011) Distributed modeling of future changes in hydrological processes of Spencer Creek watershed. Hydrological Processes 25 (8): 1254-1270. [DOI:10.1002/hyp.7891].

5. Boyer C, Chaumont D, Chartier I, Roy AG (2010) Impact of climate change on the hydrology of St. Lawrence tributaries. Journal of Hydrology 384: 65-83.

6. Dibike YB, Coulibaly $P(2005)$ Hydrologic impact of climate change in the Saguenay watershed: comparison of downscaling methods and hydrologic models. Journal of Hydrology 307 (1-4): 145-163.

7. Fowler HJ, Blenkinsop S, Tebaldi C (2007) Linking climate change modeling to impacts studies: Recent advances in downscaling techniques for hydrological modeling. Int J Climatol 27 (12): 1547-1578.

8. Praskievicz S, Chang $\mathrm{HJ}$ (2009) A review of hydrological modeling of basinscale climate change and urban development impacts. Progress in Physical Geography 33 (5): 650-671.

9. Prudhomme C, Reynard N, Crooks S (2002) Downscaling of global climate models for floodfrequency analysis: Where are we now? Hydrol. Processes 16 (6): $1137-1150$

10. Kalra A, Ahmad S (2011) Evaluating changes and estimating seasonal precipitation for Colorado River Basin using stochastic nonparametric disaggregation technique. Water Resour Res 47: W05555.

11. Sharma M, Coulibaly P, Dibike $Y$ (2011) Assessing the need for downscaling RCM data for hydrologic impact study. Journal of Hydrologic Engineering 16 534-539. [DOI:10.1061/(ASCE)HE.1943-5584.0000349].

12. Mpelasoka FS, Chiew FHS (2009) Influence of rainfall scenario construction methods on runoff projections. J Hydrometeor 10: 1168-1183. [DOI:10.1175/2009JHM1045].

13. Samuel J, Coulibaly P, Metcalfe RA (2012) Evaluation of future flow variability in ungagged basins: Validation of combined methods. Advances in Water Resources 35: 121-140.

14. Payne JT, Wood AW, Hamlet AF, Palmer RN, Lettenmaier DP (2004) Mittigating the effect of climate change on the water resources of the Coumbia river basin, Clim Change 62: 233-256.

15. Ines AVM, Hansen JW (2006) Bias correction of daily GCM rainfall for crop simulation studies. Agricultural and Forest Meteorology 138: 44-53.

16. Mearns LO, Gutowski WJ, Jones R, Leung LY, McGinnis S, et al. (2009) A regional climate change assessment program for North America. EOS 90: 311 312 .

17. Ahmed S, Coulibaly P, Tsanis I (2015) Improved spring peak-flow forecasting using ensemble meteorological predictions. Journal of Hydrologic Engineering 20 (2): 04014044 [DOI:10.1061/(ASCE)HE.1943-5584.0001014].

18. Liu X, Coulibaly $P$ (2011) Downscaling ensemble weather predictions for improved week-2 hydrologic forecasts. Journal of Hydrometeorology 12 (6): 1564-1580.

19. HRCA (1990) Hamilton Region Conservation Authority - MacLaren Plansearch Lavalin, Technical Report: Canada/Ontario Flood Damage Reduction Program.

20. NARCCAP (2013) North American Regional Climate Change Assessment Program. <http://www.narccap.ucar.edu/> (January26, 2013). 
Citation: Ahmed S, Tsanis I (2016) Watershed Response to Bias-Corrected Improved Skilled Precipitation and Temperature under Future Climate - A Case Study on Spencer Creek Watershed, Ontario, Canada. Hydrol Current Res 7: 246. doi:10.4172/2157-7587.1000246

21. Mearns LO et al. (2007) updated 2012. The North American Regional Climate Change Assessment Program dataset, National Center for Atmospheric Research Earth System Grid data portal, Boulder, CO. Data downloaded 201407-07. [DOI:10.5065/D6RN35ST].

22. Nakicenvoic N, Davidson O, Davis G, Grübler A, Kram T, et al. (2000) Special Report on Emissions Scenarios. A Special Report of Working Group III of the Intergovernmental Panel on Climate Change. Cambridge University Press, Cambridge, p: 599.

23. Mailhot A, Beauregard I, Talbot G, Caya D, Biner S (2012) Future changes in intense precipitation over Canada assessed from multi-model NARCCAP ensemble simulations. Int J Climato 32: 1151-1163.

24. Music B, Caya D (2007) Evaluation of the hydrological cycle over the Mississippi River Basin as simulated by the Canadian regional climate model (CRCM). J Hydrometeor 8: 969-988.

25. Jones R, Noguer M, Hassell D, Hudson D, Wilson S, et al. (2004) Generating high resolution climate change scenarios using PRECIS. Met Office Hadley Center. Exter, p: 40.

26. Elguindi N, Bi X, Giorgi F, Nagarajan B, Pal J, et al. (2007) RegCM Version 3.1 User's Guide, Trieste, Italy <https://users.ictp.it/RegCNET/regcm.pdf) (July 9, 2015)

27. Giorgi F, Marinucci MR, Bates GT (1993) Development of second generation regional climate model (RegCM2) I: boundary layer and radiative transfer processes. Mon Weather Rev 121: 2794-2813.

28. Skamarock WC, Klemp JB, Dudhia J, Gill DO, Barjer DM, Wang W, Powers JG (2005) A description of the advanced research WRF Version 2, NCAR Tech Notes-468+STR <http://www.mmm.ucar.edu/wrf/users/docs/arw_v2.pdf> (January 25, 2016)

29. Collins WD, Bitz CM, Blackmon ML, Bonan GB, Bretherton CS, et al. (2006) The community climate system model version 3 (CCSM3). J Climate 19: 21222143.

30. Flato GM (2005) The Third Generation Coupled Global Climate Mode (CGCM3) <http://www.ec.gc.ca/ccmac-cccma/default.asp?n=1299529F-1> (August 9, 2015)

31. Anderson JL, Balaji V, Broccoli AJ, Cooke WF (2004) The New GFDL global atmospheric and land model AM2-LM2: Evaluation with prescribed SST simulations. J Climate 17: 4641-4673.

32. Gordon C, Cooper C, Senior CA, Banks H, Gregory JM, et al. (2000) The simulation of SST, sea ice extents and ocean heat transports in a version of the Hadley Centre coupled model without fluxadjustments. Climate Dynamics 16: $147-168$.

33. Pope VD, Gallani ML, Rowntree PR, Stratton RA (2000) The Impact of new physical parameterizations in the Hadley Centre climate model-HadAM3. Climate Dynamics 16: 123-146.
34. Murphy AH, Brown BG, Chen Y (1989) Diagnostic verification of temperature forecasts. Weather Forecasting 4 (4): 485-501.

35. Wilks DS (2000) Diagnostic verification of the Climate Prediction Center long lead outlooks, 1995-1998. Journal of Climate 13 (13): 2389-2403.

36. Hartmann HC, Pagano TC, Bales R, Sorooshian S (2002) Confidence builders: Evaluating seasonal climate forecasts from user perspectives. Bull. American Meteorological Society 83: 683-698.

37. Brier GW (1950) Verification of forecasts expressed in terms of probabilities. Monthly Weather Review 78: 1-3.

38. Renner M, Werner MG, Rademacher S, Sprokkereef E (2009) Verification of ensemble flow forecasts for the river Rhine. Journal of Hydrology 376 (3-4): 463-475.

39. Roulin E (2007) Skill and relative economic value of medium-range hydrologica ensemble predictions. Hydrology and Earth System Sciences 11 (2): 725-737.

40. Mullen SL, Buizza R (2011) Quantitative precipitation forecasts over the United States by the ECMWF ensemble prediction system. Mon Weather Rev 129 (4): 638-663.

41. Clark MP, Hay LE (2004) Use of medium-range numerical weather prediction model output to produce forecasts of streamflow. Journal of Hydrometeorology 5 (1): 15-32.

42. Gangopadhyay S, Clark M, Brandon D, Wener K, Rajagopalan B (2004) Effects of spatial and temporal aggregation on the accuracy of statistically downscaled precipitation estimates in the upper Colorado river basin. Journa of Hydrometeorology 5 (6): 1192-1206.

43. Sharma M (2009) Comparison of downscaled RCM and GCM data for hydrologic impact assessment. MASc Thesis, Department of Civil Engineering, McMaster University, Hamilton, Ontario, Canada.

44. Bergstrom S (1991) Principles and confidence in hydrological modelling. Nordic Hydrology 22: 123-136.

45. Lindstrom G, Johansson B, Magnus P, Gardelin M, Bergstrom S (1997) Development and test of the distributed HBV-96 hydrological model. Journal of Hydrology 201: 272-288.

46. Swedish Meteorological and Hydrological Institute (SMHI) (2012) Integrated hydrological modelling system manual, version 6.3. Norrköping, Sweden.

47. Nash JE, Sutcliffe JV (1970) River flow forecasting through conceptual models Part I - a discussion of Principals. Journal of Hydrology 10: 282-290.

48. Coulibaly P, Anctil F, Bobee B (2001) Multivariate reservoir inflow forecasting using temporal neural networks. Journal of Hydrologic Engineering 6: 367-376.

49. Zahmatkesh Z, Karamouz M, Goharian E, Burian SJ (2015) Analysis of the effect of climate change on urban storm water runoff using statistical downscaled precipitation data and a change factor approach. Journal of Hydrologic Engineering 20: 05014022. [DOI: 10.1061/(ASCE)HE.19435584.0001064] 